ARTIGO

\title{
Pesquisa como princípio educativo: uma metodologia de trabalho para a Educação de Jovens e Adultos
}

\author{
Cecília de Sousa Reibnitz ${ }^{a}$ \\ Ana Carolina Staub de Melo ${ }^{b}$
}

\section{Resumo}

A modalidade de Educação de Jovens e Adultos (EJA) atinge apenas uma pequena parcela de sua demanda, sendo que um dos importantes fatores que leva o público a não frequentar as classes escolares é a inadequação de metodologias e de conhecimentos às suas realidades e objetivos. Na Rede Municipal de Ensino de Florianópolis (SC), desenvolve-se uma forma de trabalho escolar diferente, que procura atender a essa necessidade: a pesquisa como princípio educativo. $\mathrm{O}$ objetivo deste artigo é analisar essa metodologia, adotada pela rede desde 2001, perpassando seu desenvolvimento, seus referenciais teóricos e algumas reflexões sobre a prática escolar cotidiana. Além da pesquisa teórica, o artigo utiliza-se de relatos de experiência de sala de aula e da análise de textos produzidos por alguns estudantes no ano de 2018, procurando demonstrar algumas potencialidades e limites da prática. Assim, acredita-se que, a partir do aprofundamento dessa metodologia, é possível analisar melhor algumas demandas e questões pertinentes à EJA no país. Palavras-chave: Educação de Jovens e Adultos. Pesquisa como Princípio Educativo. Práticas pedagógicas.

Na Rede Municipal de Ensino de Florianópolis/SC (RMEF), os anos finais do Ensino Fundamental da Educação de Jovens e Adultos (EJA) possuem uma metodologia diferente: é a chamada "pesquisa como princípio educativo". O foco das aulas é o desenvolvimento de pesquisa pelos estudantes e, nesse percurso, os professores atuam como mediadores, auxiliando individualmente, ou em pequenos grupos, propondo intervenções para a turma, que servem como ampliações das pesquisas. A forma não seriada e não disciplinar da EJA é incomum, sendo um projeto próprio da rede em questão. Sua singularidade, inclusive, foi o que

\footnotetext{
a Instituto Federal de Santa Catarina, Florianópolis, SC, Brasil.

b Instituto Federal de Santa Catarina, Florianópolis, SC, Brasil. 
estimulou este estudo conhecer essa organização de ensino. Assim, o presente artigo é um recorte de uma pesquisa desenvolvida no trabalho de conclusão de curso de especialização em Educação Profissional Integrada à Educação Básica na Modalidade de EJA (Proeja) do Instituto Federal de Santa Catarina (IFSC).

A EJA da Rede Municipal de Ensino de Florianópolis possui a pesquisa como princípio educativo desde 2001. O objetivo deste artigo é abordar essa metodologia de trabalho realizada em Florianópolis, tanto no que se refere à sua concepção teórica quanto aos desafios, potencialidades e limites no contexto escolar. O texto também traz relatos de experiência da sala de aula e analisa textos produzidos por 12 alunos da rede em questão no ano de 2018, de modo a procurar dar voz aos sujeitos estudantes da EJA. Acredita-se que, a partir do aprofundamento da metodologia da pesquisa como princípio educativo, é possível analisar melhor algumas demandas e questões pertinentes à EJA no país.

A importância da pesquisa advém do problema da grande demanda de EJA no país em contraposição à pequena parcela populacional que essa modalidade atinge. Além da falta de investimentos e de políticas públicas na área, um dos grandes fatores que leva o público a não frequentar as classes escolares é a inadequação de metodologias e conhecimentos às suas realidades e objetivos.

Certamente, não é possível pensar um único projeto de EJA baseado nesse modelo, principalmente porque as demandas e as necessidades da população nessa modalidade de ensino são muito diversificadas e não seria possível imaginar a aplicação de uma fórmula em larga escala. Contudo, a proposta pedagógica da RMEF pode ser um sistema que ajude a refletir sobre metodologias de outras redes de EJA ou de outros projetos - assim como, por outro lado, outras metodologias podem contribuir para melhorar ou modificar práticas da rede municipal, alvo deste estudo.

Dentro das políticas públicas da Educação, a modalidade EJA é historicamente desprivilegiada. Os recursos financeiros fornecidos pelo Ministério da Educação (MEC), por exemplo, têm sofrido uma queda acentuada, sendo que o ano de 2019 foi o menor orçamento da década - foram destinados R \$16,6 milhões, o correspondente a apenas $22 \%$ dos $\mathrm{R} \$ 74$ milhões que eram previstos para aquele ano. Para 2020, a previsão aponta cerca de $\mathrm{R}$ \$ 25 milhões. Mesmo com a suposição otimista de que todo o valor seja aplicado, o número é ainda muito menor do que se investiu em anos anteriores - em 2012, por exemplo, o orçamento na área foi de $\mathrm{R} \$ 1,6$ bilhão ${ }^{1}$.

\footnotetext{
Informações encontradas em várias notícias divulgadas no início do ano de 2020, entre elas: "Educação de Jovens e Adultos tem, em 2019, o menor investimento da década", disponível em: https://oglobo.globo. com/sociedade/educacao-de-jovens-adultos-tem-em-2019-menor-investimento-da-decada-24162835. Acesso em: 10 fev. 2020.
} 
Além dos cortes nos investimentos, a secretaria responsável pela EJA dentro do MEC, denominada Secretaria de Educação Continuada, Alfabetização, Diversidade e Inclusão (Secadi), foi dissolvida em 2019 e as novas secretarias criadas em seu lugar não contemplam a modalidade de EJA. Tampouco a EJA é devidamente mencionada na atual Política Nacional de Alfabetização, e a referência a essa modalidade apenas é presente quanto ao desenvolvimento de materiais didáticopedagógicos - por sinal, atente-se que a última distribuição de livros didáticos na modalidade se deu em $2016^{2}$.

Um estudo que serve como referência para a compreensão das políticas públicas na história da EJA do Brasil é o realizado por Haddad e Di Pierro (2000). Os autores analisam a oferta da Educação de Adultos desde o período colonial, com ênfase no ensino supletivo desenvolvido a partir da década de 1970 e as mudanças das concepções no período da redemocratização. Naquele momento, a EJA foi "marcada pela contradição entre a afirmação no plano jurídico do direito formal da população jovem e adulta à Educação Básica, de um lado, e sua negação pelas políticas públicas concretas, de outro" (HADDAD; DI PIERRO, 2000, p. 12).

Com relação aos conteúdos e métodos, um grande problema da EJA é que, muitas vezes, a situação tenta ser "contornada" de forma equivocada, de modo que são trabalhados os mesmos conteúdos da escola convencional, mas de forma condensada. Conforme analisa Arroyo (2017, p. 142):

A função prevista para a EJA - reparar os percursos não feitos no tempo regular dos ensinos Fundamental e Médio - tem levado a reaproveitar, a requentar o cardápio intelectual dos currículos dessas etapas. Tem levado a não termos um currículo específico para a educação das pessoas jovens-adultas que vêm do trabalho.

Muitas vezes os jovens e os adultos são vistos como se fossem crianças ou incapazes, o que acarreta infantilização dos sujeitos e tematização de conteúdos que não fazem sentido para suas vidas. Essas visões desconsideram as trajetórias e os conhecimentos dos alunos de EJA - suas especificidades exigem que se pense a Educação de outra maneira.

A visão tradicional de currículo é bastante discutida pelo sociólogo e educador espanhol Arroyo que, em diferentes estudos, mostra como os currículos são

2 Informação também disponível em diferentes notícias, entre elas: "'A EJA não tem lugar no MEC atualmente', afirma Sonia Couto", disponível em: https://www.geledes.org.br/a-eja-nao-tem-lugar-no-mec-atualmenteafirma-sonia-couto/. Acesso em: 13 mar. 2020. 
territórios de disputa e coloca-se contra a visão dos conhecimentos escolares como sacralizados e intocáveis. De acordo com o autor, o caso é ainda mais grave na EJA "onde chegam as pessoas jovens-adultas com longas experiências de trabalho, de intervenção na vida cotidiana. Chegam com outros saberes" (ARROYO, 2017, p. 149). Tais saberes dificilmente são reconhecidos, dado o viés hierárquico como se entende o conhecimento na docência e nos currículos. Assim, Arroyo questiona o currículo de base comum, que traduz um conhecimento único - apontando-o, inclusive, como um dos motivos que leva à reprovação escolar.

Os sujeitos que, de alguma forma, não se adaptaram aos ensinamentos padronizados tornam-se excluídos da escola dita convencional para ingressar na EJA. Foi o caso de Ricardo, nome fictício de um jovem estudante, matriculado na EJA da RMEF em 2018.

Antes de ingressar na EJA estava sem perspectiva e sem foco [...] Quando eu repeti o $6^{\circ}$ ano pela primeira vez, em 2010 não conseguia mais terminar o Ensino Fundamental, não por falta de oportunidade, mas por falta de interesse em ir pra escola, pois recomeçava o ano letivo e parava na metade do ano e muitas vezes eu trabalhava e não ia para a escola (Ricardo).

Como já dito, o presente trabalho utiliza fragmentos de textos escritos por alunos no final de 2018. As redações, no total 12 , foram feitas por alguns dos estudantes que estavam certificando-se em uma das turmas em que uma das autoras lecionava. Pediu-se que escrevessem sobre sua trajetória escolar antes de ingressar na EJA, que realizassem uma reflexão sobre a passagem pela EJA e que apontassem quais as próximas etapas da vida/estudos/trabalho que pretendiam realizar. Os textos foram feitos durante as aulas como um dos mecanismos de avaliação, mas a riqueza desse material impulsionou a presente pesquisa e contribuiu para o gesto de fazer ressoar algumas vozes neste artigo.

O descontentamento com relação às escolas convencionais também foi expressado por Cristiane, outra jovem estudante:

Aqui na EJA aprendi bastante mesmo com pouco tempo de estar aqui, me deu mais vontade de estudar, não é chato igual a escola kkk, é muito legal. Nós aprendemos bastante com a pesquisa, gostei muito de estudar aqui e dos professores, aprendi a me desenvolver com minhas pesquisas e dos meus colegas, tenho vergonha de falar em público mas aprendi bastante na leitura e na escrita (Cristiane). 
Os dois estudantes demonstram contentamento com a EJA, em contraste com as escolas convencionais onde estudaram anteriormente - tidas como desinteressantes e que não atendiam suas necessidades ou não estimulavam o estudo. O segundo depoimento enfatiza a prática da pesquisa como princípio educativo e demonstra satisfação com o modelo. Há que se destacar que a EJA é marcada por uma grande pluralidade de sujeitos, os quais, muitas vezes, têm opiniões diferentes sobre as formas de estudo. É recorrente, nas salas da EJA da RMEF, que alunos peçam por aulas mais tradicionais no lugar das pesquisas desenvolvidas, como se verá adiante. Os relatos expressam sempre a visão de cada sujeito e, por se tratarem de estudantes que estavam certificando-se, considera-se que são alunos que, ao menos em alguma medida, adaptaram-se bem à metodologia da pesquisa.

A demanda de EJA no Brasil é muito grande: de acordo com os dados de 2016 do Instituto Brasileiro de Geografia e Estatística (IBGE), quase metade da população adulta (49\%) com mais de 25 anos não concluiu o Ensino Fundamental. Visto que a EJA atende jovens a partir de 15 anos, observa-se que há uma faixa etária contemplada por essa modalidade de ensino que não foi especificada na pesquisa e que sua inclusão aumentaria ainda mais as estatísticas. Os dados tornam-se ainda mais impressionantes quando considerado fatores como raça, classe, idade e região ${ }^{3}$.

Contudo, menos de 5\% daqueles que não concluíram a Educação Básica estão frequentando uma escola, de acordo com Catelli Júnior. Na cidade de São Paulo, por exemplo, de acordo com estudos de Di Pierro, Catelli Junior e Girotto (2019, p. 466), a EJA possui "índice de cobertura de cerca de $4 \%$ da demanda potencial". Já em Florianópolis, o estudo mais recente encontrado a abordar esses números é o de Passos (2010). A autora afirma que, segundo levantamento feito pela Secretaria Municipal de Saúde em 2007, 11\% da população total de Florianópolis não havia completado o Ensino Fundamental, "no entanto, conforme informação do Departamento de Educação Continuada da Secretaria Municipal de Educação, nos últimos anos, tem sido atendida em torno de 3,5\% dessa demanda" (PASSOS, 2010, p. 179).

\footnotetext{
Os dados de 2016 exploram algumas dessas perspectivas, principalmente em termos de raça e região, como pode ser consultado em: https://agenciadenoticias.ibge.gov.br/agencia-sala-de-imprensa/2013-agencia-denoticias/releases/18992-pnad-continua-2016-51-da-populacao-com-25-anos-ou-mais-do-brasil-possuiamapenas-o-ensino-fundamental-completo (Acessado em: 22 jan. 2019). A pesquisadora Maria Margarida Machado examina ainda mais a questão a partir dos índices de 2009: "Os dados da Pnad/2009 indicam que o $1^{\circ}$ quinto da população mais pobre do país apresenta média de 5,5 anos de estudos, comparado a 10,7 anos de estudos do $5^{\circ}$ quinto da população mais rica. Entre os jovens de 25 a 29 anos a média de estudos é de 9,4 anos, enquanto na população de 40 anos e mais, a média de anos de estudos é de 6,2 anos. Do ponto de vista da diversidade étnico racial, negros possuem 6,7 anos de estudos em comparação a 8,4 anos de estudos dos brancos. Na área rural, a média de anos de estudos é de 4,8, ao passo que nas regiões metropolitanas os anos de estudos chegam a 8,7. Finalmente, ainda prevalecem significativas diferenças regionais, pois no Sudeste a média de estudos é de 8,2 anos e no Nordeste é 6,3 anos" (MACHADO, 2011, p. 395).
} 


\section{A pesquisa como princípio educativo}

Um dos documentos que norteiam a metodologia da pesquisa como princípio educativo na EJA da RMEF é o "Caderno do Professor", publicado em 2008, com o título de "Estrutura, Funcionamento, Fundamentação e Prática na Educação de Jovens e Adultos EJA - 2008". O material foi desenvolvido pelo Departamento de Formação Continuada - responsável, dentre outras coisas, por realizar os cursos de formação mensal de todos os professores da rede. Seu objetivo é "trazer conteúdos que acreditamos importantes para quem atua na Educação de Jovens e Adultos da Prefeitura de Florianópolis" (FLORIANÓPOLIS, 2008, p. 4), contemplando tanto aspectos teóricos como as características e a fundamentação do curso de EJA.

Nesse sentido, o Caderno apresenta a proposta da pesquisa como princípio educativo, suas etapas e seus métodos de avaliação. Apesar de ter sido publicado em 2008, o texto é, até hoje, o principal documento a ser apresentado para o corpo docente no início do ano letivo, uma vez que a maioria é constituída por professores substitutos e há uma grande rotatividade de profissionais

A introdução do material afirma que também "apresenta-se uma bibliografia que faz parte do cotidiano da EJA de Florianópolis e que é motivo permanente de reflexão. Sugere-se buscar algumas daquelas referências, por exemplo, o texto sobre a Escola da Ponte de Rubem Alves e os textos sobre legislação" (FLORIANÓPOLIS, 2008, p. 4). Nesses referenciais teóricos, são citados livros, revistas e anais de eventos de onde os textos que compõem o Caderno foram tirados, além de algumas leis e resoluções, dentre outros textos. Apenas um livro de Paulo Freire é mencionado e aparecem poucas menções ao educador ao longo do material, porém, percebe-se que a proposta dialoga bastante com suas reflexões, sendo o autor uma referência que costuma aparecer nos cursos de formação continuada realizados na rede.

Ainda nas referências, destacam-se o número de citações de José Manoel Cruz Pereira Nunes, autor de cinco dos textos do Caderno. Esse professor era, quando da edição do material, o chefe do Departamento de Educação Continuada. A Escola da Ponte, criada em Portugal, apesar de ser mencionada apenas na introdução do documento, é também uma inspiração para a prática desenvolvida na RMEF: seu método de ensino baseia-se na pesquisa e foi idealizada e coordenada por José Pacheco durante 28 anos, sendo referência na área.

Também com cinco menções nas referências, há o nome de Pedro Demo, autor que ofereceu contribuições ao entendimento do papel da pesquisa para a EJA. Segundo Demo, "o que melhor distingue a Educação escolar de outros tipos e 
espaços educativos é o 'fazer-se' e 'refazer-se' "na' e "pela pesquisa" (DEMO, 1996, p. 5). Não seria a aula e, sim, a pesquisa a base e a propriedade específica da Educação. De acordo com o autor, deve ser esse o princípio da Educação em seus diferentes níveis, seja o Ensino Superior ou o Fundamental, cada estágio dentro de seus próprios horizontes.

O sentido e a potência vistos na pesquisa assemelham-se à concepção de ensino de Freire (1996, p. 22): “ensinar não é 'transferir conhecimento', mas criar possibilidades para sua produção ou sua construção". Freire também valoriza e enfatiza o papel da pesquisa:

Não há ensino sem pesquisa e pesquisa sem ensino. [...] Ensino porque busco, porque indaguei, porque indago e me indago. Pesquiso para constatar, intervenho, intervindo educo e me educo. Pesquiso para conhecer o que ainda não conheço e comunicar ou anunciar a novidade (FREIRE, 1996, p. 29).

É a pesquisa que permite a ampliação do conhecimento em sua dimensão ativa e crítica. Para Pedro Demo, a partir dessa metodologia é possível conhecer e interferir no mundo, o que proporciona um posicionamento político, com formação de sujeito crítico e criativo. Essa seria uma dimensão emancipatória da Educação, atribuindo papel ativo ao estudante que questiona o mundo, procura respostas e interferências - "a característica emancipatória da Educação, portanto, exige a pesquisa como seu método formativo, pela razão principal de que somente um ambiente de sujeitos gesta sujeitos" (DEMO, 1996, p. 8).

Um dos alunos jovens de 2018 escreveu sobre sua experiência na EJA: "Acho que foi muito importante pra mim porque aprendi coisas diferentes e também foi um estímulo ver pessoas mais velhas que eu focadas nos estudos e isso eu vou levar pra minha vida toda. Eu aprendi a ser mais maduro quanto a isso" (Lucas). Ou seja, todo o ambiente e toda a convivência com colegas de diferentes idades e origens contribuíram positivamente para sua formação. As experiências na EJA permitiram observar a existência de conflitos geracionais em sala, principalmente no início dos anos, mas, por outro lado, às vezes esses embates pouco a pouco, transformavam-se em companheirismos, por exemplo, quando, em duplas de pesquisa, um aluno jovem juntava-se a outro adulto.

Nas aulas de EJA da RMEF, o comprometimento com um ambiente de aprendizagem deve passar por todos. Os professores aprendem com os alunos, juntos pesquisam, muitas vezes a partir de temas não imaginados. A tarefa com o 
estudante é orientá-lo em certos caminhos, estimular a sua curiosidade, auxiliar na busca por materiais (textos, vídeos, imagens, mapas, gráficos, fazer entrevistas ou questionários, entre outros), organizar e sistematizar o conhecimento, auxiliar a elaborar textos e conclusões próprias etc. Segue-se, talvez, o caminho proposto por Demo (1996, p. 2): “não se busca um 'profissional da pesquisa', mas um "profissional da educação pela pesquisa"”. Assim, ao realizarem investigações com os alunos, os professores vão também se formando.

\section{A construção do modelo da EJA na RMEF}

De acordo com o documento da proposta curricular da Rede Municipal de Ensino de Florianópolis (ZANELA; BARCELOS, 2016), a Educação de Jovens e Adultos é oferecida desde a década de 1970. Atualmente, o curso é destinado para jovens e adultos a partir de 15 anos que desejam concluir o Ensino Fundamental e divide-se em primeiro segmento (para as séries iniciais) e segundo segmento (para as finais). O presente trabalho refere-se ao funcionamento apenas do segundo segmento, no qual atuam professores de diferentes áreas. O primeiro segmento, por sua vez, tem como metodologia a "leitura como princípio educativo", é destinado à alfabetização e possui um professor(a) pedagogo(a) como responsável, apesar da intenção de integração entre professores e alunos de um mesmo núcleo.

O modelo de trabalho da pesquisa como princípio educativo foi desenvolvido já a partir do ano 2000 por meio de projetos de pesquisa nas classes de aceleração do Ensino Fundamental. A experiência, relatada como bem-sucedida no texto da proposta curricular, foi introduzida também na EJA: se inicialmente apenas em alguns poucos núcleos, a partir de 2001, todas as turmas de EJA da rede adotaram a pesquisa como princípio educativo.

Com isso, "a EJA passou a demandar nova estrutura organizativa e pedagógica para dar conta do que essa concepção de ensino apontava" (ZANELA; BARCELOS, 2016, p. 243) $)^{4}$. Para viabilizar a proposta, professores do segundo segmento possuem uma jornada de trabalho específica. A maioria é composta de professores substitutos (admitidos em caráter temporário - ACT), sendo que a reivindicação por concurso público na área é de longa data. Os profissionais possuem, no geral, contrato de 30 horas semanais, durante um ano letivo, para trabalhar em determinado núcleo de EJA que atende, quase sempre, mais um ou dois polos - podem ser escolas, associações ou similares ${ }^{5}$.

\footnotetext{
4 A regulamentação e estabelecimento das normas operacionais da EJA da RMEF está na Resolução n 02/2010 do Conselho Municipal de Educação.

5 Havia nove núcleos de EJA em exercício na cidade no ano de 2018 atendendo em cerca de 26 polos. A quantidade e a localização dos núcleos e dos polos costumam variar a cada ano.
} 
São realizadas duas reuniões de planejamento e formação semanais envolvendo professores, coordenador, articuladores, dentre outros, nas quais são discutidas questões metodológicas e pedagógicas, tais como: forma de condução das pesquisas, planejamento semanal, escala dos professores em cada polo, propostas de oficinas, saídas de estudo, questões teóricas sobre a EJA e determinadas condutas disciplinares. Atende-se aos alunos de segunda à sexta-feira no período noturno, com exceção de um dos núcleos que atua durante o dia e de alguns polos que não oferecem aulas nos cinco dias da semana.

A proposta de desenvolvimento de pesquisas alinha-se a uma determinada estrutura. Em suas pesquisas, os estudantes devem escrever uma problemática, uma justificativa e um mapa da pesquisa, dentre outros passos, antes de iniciar a produção de dados e chegar às conclusões.

A problemática é a questão que irá nortear toda a pesquisa e que é escolhida pelos alunos. Nesse sentido, não há perguntas "erradas" ou que não possam ser trabalhadas nas orientações, apenas cuida-se para que elas sejam bem formuladas e correspondam às justificativas sobre o que desejam aprender, de modo que a pesquisa possa ser significativa para suas vidas. A pesquisa pode ser feita de forma individual, em duplas ou em trios, desde que a problemática seja do interesse de todos. Ao final, os grupos devem escrever um relatório e preparar uma apresentação. Esses são alguns dos pontos fundamentais que orientam a metodologia de todos os núcleos, porém, há flexibilidade na execução do método, podendo ser desenvolvidas diferentes estratégias, de acordo com as demandas e a equipe de cada local.

O trabalho com problemáticas é um assunto importante na proposta. Diz-se que a EJA é uma escola de perguntas, muito mais do que de respostas. No livro "Por uma Pedagogia da Pergunta", Freire e Faudez (1985) tecem um diálogo a respeito da importância do ato de perguntar na Educação. Faundez ressalta que

No ensino esqueceram-se das perguntas, tanto o professor como o aluno esqueceram-nas, e no meu entender todo conhecimento começa pela pergunta. Começa pelo que você, Paulo, chama de curiosidade. Mas a curiosidade é uma pergunta! (FREIRE; FAUDEZ, 1985, p. 24).

Os autores criticam o fato de que grande parte dos educadores já traz para os alunos a resposta para algo que sequer foi questionado, enquanto deveria ser feito o oposto: ensinar em primeiro lugar a perguntar. Quando o professor parte 
das respostas, não há espaço para a curiosidade e a investigação. É nesse sentido que se valoriza o papel das problemáticas como o motor das pesquisas na EJA e, por isso, "para um educador nesta posição não há perguntas bobas nem respostas definitivas" (FREIRE; FAUDEZ 1985, p. 25).

Também no "Caderno do Professor" (2008), ressalta-se a importância do ato de perguntar dentro do próprio currículo:

Um currículo onde os conteúdos procedimentais e atitudinais são tão ou mais importantes que os conceituais. Que os conteúdos "formular uma pergunta", "resolver problemas" e "pesquisar" fazem parte do nosso cotidiano (FLORIANÓPOLIS, 2008, p. 7).

A pesquisa, conforme exposto, é o principal eixo da prática pedagógica, mas há também outras atividades e situações. No início do período letivo, são feitos encontros que procuram promover o acolhimento e permitem que colegas e professores da turma se conheçam. Ao longo de todo o ano, é comum a prática de oficinas, nas quais determinados temas ou ferramentas mobilizadas nas pesquisas são tratadas. Os alunos possuem diários individuais, nos quais é estimulada a prática da escrita, tanto relativa a temas pessoais quanto a determinados assuntos debatidos em sala. Podem ainda acontecer "palestras por professores e pela comunidade, cursos, confraternizações, saídas pedagógicas, estudos dirigidos, atividades esportivas etc." (FLORIANÓPOLIS, 2008, p. 13).

Assim, o modelo pretendido para a EJA não é aquele em que o professor é visto como porta-voz da transmissão de conhecimentos. Os alunos socializam suas pesquisas com a turma e são proporcionadas vivências em teatros, cinemas e espaços que não costumavam frequentar - inclusive ocupar a cidade e participar de eventos culturais são considerados importantes na EJA, visto que muitas vezes os sujeitos que os frequentam sentem como se tais espaços não os pertencessem, mesmo quando públicos ou gratuitos. Uma das alunas relatou em seu texto: "aqui aprendi muito com apresentações de trabalho de meus colegas, palestras e muito mais" (Catarina).

O sistema de presença se dá mediante a marcação de horas - que é um dos instrumentos de avaliação diária dos alunos. A carga horária do segundo segmento da EJA é de 1.600 horas-aula "efetivamente trabalhadas". Isso significa que, mesmo que os alunos estejam na escola, só irão receber horas se estiverem, de fato, envolvidos na pesquisa ou nas atividades propostas. São computadas até quatro horas para cada dia letivo de acordo com o envolvimento do estudante. A essas horas podem ser somadas outra carga horária referente ao histórico escolar, sendo 
200 horas para cada ano completo dos anos finais do Ensino Fundamental que o estudante tenha cursado anteriormente ou, ainda, o histórico de outros núcleos de EJA. Uma parcela da carga horária também pode ser feita de forma não presencial (até 200 horas). Trata-se das chamadas "horas de produção externa", geralmente materializadas na forma de textos autorais, desenhos, relatos de filmes, pequenas pesquisas ou outras produções feitas fora da escola - esses trabalhos são avaliados pelos professores, corrigidos, comentados e recebem determinado número de horas considerando o tempo aproximado que o aluno levou para realizá-lo.

São muitos os alunos de EJA que não possuem disponibilidade para uma frequência assídua na escola, principalmente devido a fatores como trabalho, família e moradia, de modo que, por meio desse sistema de horas, há maior flexibilidade para conciliar frequência com essas questões. Os alunos também recebem valetransporte e uma refeição é oferecida no intervalo, o que é essencial para aqueles que chegam direto do trabalho e possuem baixa renda. Assim, possibilita-se que os estudantes concluam os estudos em tempos diferentes - não há "reprovação", mas, sim, um acúmulo de horas necessárias para a certificação.

Há casos em que alunos são certificados antes de completar toda a carga horária, o que se dá por meio das avaliações - "a avaliação é processual, permanente, dialógica e registrada de várias formas todos os dias" (FLORIANÓPOLIS, 2008, p. 21) - nas quais se considera, entre outras coisas, o letramento, a oralidade, a iniciativa e a autonomia. Também são variados os instrumentos avaliativos, como o caderno de pesquisa, os cadernos individuais, chamados diários, a participação e o envolvimento nas aulas etc.

\section{A pesquisa na prática cotidiana escolar}

A prática da pesquisa como princípio educativo é desenvolvida de diferentes maneiras, a considerar a equipe de profissionais do núcleo, o perfil dos estudantes e a disponibilidade de materiais e de espaços escolares. Relatam-se aqui algumas impressões e experiências vividas por uma das autoras durante os quatro últimos anos em diferentes núcleos, aliadas a pesquisas envolvendo a EJA na RMEF. Embora nenhum trabalho acadêmico dedique-se especificamente às impressões dos alunos quanto à metodologia da pesquisa, alguns depoimentos abordam a questão, principalmente nos trabalhos de Passos (2010), Berger (2009) e Nunes (2010) que entrevistaram estudantes e ex-estudantes da EJA de Florianópolis.

Apesar de muitas vezes os estudantes da EJA serem alunos que, de alguma forma, não se adaptaram aos conhecimentos padronizados pela escola tradicional conforme o exposto por Miguel Arroyo -, paradoxalmente, ao chegar na EJA, 
muitos deles solicitam essa metodologia e esses conhecimentos, demonstrando, por vezes, resistência em tentar novos métodos de aprendizagem. Como afirma Feitosa, cuja pesquisa buscou, justamente, analisar se os sujeitos da EJA estavam sendo considerados dentro da formulação das matrizes curriculares, "qualquer experiência que se distancie do imaginário que eles têm de escola, de educador, de aprendizagem é rejeitada por eles" (FEITOSA, 2012, p. 155).

Acredita-se que tal concepção por parte dos alunos que não veem a produção de algo significativo com sua pesquisa está atrelada a uma ideia tradicional de ensino, caracterizada pela adoção de uma postura mais passiva por parte dos alunos que esperam que professores "tragam respostas". Por outro lado, é importante que se ofereça aos estudantes a possibilidade de visualizar de forma mais direta as diferentes áreas e os conteúdos que envolvem cada pesquisa, o que poderia ajudá-los a mitigar sua angústia e a relacionar sua pesquisa com o saber institucionalizado.

Berger (2009), que já foi responsável pelo Departamento de EJA, relata em sua dissertação a forma como alguns alunos que entrevistou se referiam à metodologia da pesquisa: "ao sistematizar as informações, percebi que os estudantes demonstraram dificuldades em avaliar o projeto e apresentavam respostas muito genéricas. Nas entrevistas, no entanto, demonstraram algumas inquietações quanto a alguns aspectos do projeto" (BERGER, 2009, p. 66). O pesquisador, então, reproduz falas de alunos que elogiavam e criticavam o modelo "os alunos vivem uma certa contradição, por um lado, reconhecem seus valores e sobretudo as experiências que ali realizam, no entanto percebem também seus limites" (BERGER, 2009, p. 67).

Já a tese de Passos (2010) teve como objetivo analisar os alcances dessa prática escolar para a juventude negra da cidade. De acordo com a autora, "os jovens apresentam diferentes olhares sobre os saberes a que têm acesso na EJA. Alguns explicitam a preocupação com a ausência dos saberes da escolarização, outros apresentam as habilidades que desenvolveram como aquisições fundamentais" (PASSOS, 2010, p. 266). Contudo, a autora aponta que a ausência dos saberes tradicionais

pode ser um dos fatores para a infrequência de jovens negros, se consideramos que eles podem estar introjetando ser a EJA uma modalidade de baixa qualidade e sem grandes perspectivas para a sua continuidade nos estudos, na medida em que percebem os saberes escolares como importantes para a continuidade dos estudos (PASSOS, 2010, p. 189). 
Além disso, Passos aponta criticamente para o fato de que a proposta da EJA trata os alunos de forma homogeneizada, sem considerar o pertencimento étnico-racial e geracional desses sujeitos. Certamente o perfil dos estudantes da EJA se modificou ao longo desses 20 anos em que se trabalha com essa metodologia e, nesse sentido, é preciso investigar melhor sobre como se lidou com os diferentes perfis discentes. Talvez algumas dessas questões estejam relacionadas à juvenilização dos sujeitos que frequentam a EJA - a metodologia, pensada no início dos anos 2000 , tinha como público um perfil de alunos mais velhos do que aqueles que hoje encontram-se nas classes de EJA. Os grupos de professores de cada núcleo, por vezes, desenvolvem estratégias interessantes para lidar com tais questões, como, por exemplo, a realização de pesquisas mais rápidas, a proposição de mais oficinas, a execução de pesquisas coletivas etc.

Um jovem estudante ressaltou em seu texto sobre a EJA: "minha antiga escola era muito diferente e mais rápida mas não me preparava para o mundo lá fora como esse novo projeto da EJA faz" (Luiz). Em seguida, explica um pouco porque se sentiu mais preparado com a EJA: "Sou uma pessoa muito tímida e não gosto muito de gente, mas apesar disso gostei, pois me ajudou bastante a me expressar em muitas entrevistas de emprego e dinâmica que a empresa pedia". Assim, para Luiz o mais significativo não foram os conteúdos e, sim, o aprendizado concernente à sua expressividade, o que lhe propiciou que se comunicasse com mais facilidade - uma habilidade de grande importância para a vida, porém não ressaltada como conhecimento escolar tradicional.

Outra aluna também destacou a importância do desenvolvimento dessa competência:

No começo pensei que seria difícil porque aqui fazem bastante dinâmica de grupo e eu era muito fechada, porém hoje eu sinto que essa dinâmica foi o que me ajudou a impor a liberdade de me expressar. Eu conheci pessoas que pensavam de outras formas e mostravam outro jeito de ver as coisas. Os professores são bem pacientes e respeitam o tempo de aprendizado de cada aluno e explicam muito bem se preciso diversas vezes nos encorajando a aprender. Aqui nós não achamos que iremos superar, nós temos certeza que vamos (Marina).

A aluna Marina conta como a habilidade de expressão e o encorajamento que recebeu foram importantes para sua vida pessoal - ela precisou parar os estudos muito jovem para cuidar da família, logo casou-se e teve filhos e, assim, seu tempo foi dedicado aos outros - seu marido, ademais, era contra sua volta aos estudos, por 
sentir ciúmes. Histórias como essa são relatadas por muitas alunas que frequentam a EJA. Marina, então, conseguiu fortalecer-se cada vez mais para buscar seu sonho: "um dia vão me conhecer como dra. Marina e meus filhos terão orgulho da mãe".

A profusão de referências à autoestima foi o que mais chamou a atenção nos textos dos alunos de 2018. As múltiplas exclusões dos alunos - seja escolar, familiar ou do mercado de trabalho - marcam suas vidas de modo a valorizarem e acreditarem muito pouco em seus conhecimentos. Em diversos momentos dos textos, há depoimentos afirmando que encontraram na EJA um lugar que os valoriza e devolve sua confiança:

Esse tempo que estudei na EJA foi muito importante para retomar a minha autoestima, pois quando se fecham portas para nós entramos em estado depressivo e ver que existem pessoas como os nossos professores que acreditam no potencial de cada um de nós aonde buscam forças para superar esse momento com sabedoria (Cristiano).

Nesse tempo que fiquei parado [22 anos sem estar na escola] ficava pensando muito em voltar vendo pessoas que eu conhecia terminando os estudos. [...] Eu ficava com vergonha [...] Então voltei a estudar e com muito orgulho gostaria de concluir os estudos, pois tenho um objetivo: fazer o magistério (Ronaldo).

No primeiro dia na EJA foi assustador, medo, porque não sabia muita coisa quase nada $[. .$.$] hoje estou aqui muito feliz com tudo o que$ aprendi e vivi, pretendo seguir em frente com meus estudos e fazer uma faculdade, a EJA me deu um empurrão para o futuro, só tenho agradecer os professores, EJA muito obrigada (Marynes).

É necessário valorizar os diversos conhecimentos trazidos pelos alunos, como coloca Miguel Arroyo, "exige reconhecer que toda experiência social produz conhecimentos, e que todos os sujeitos de experiências sociais são produtores de conhecimentos" (ARROYO, 2017, p. 138). Somente assim, serão gerados "saberes que alterem a vida cotidiana dos educandos e dos próprios educadores. Saberes que lhes garantam o direito a entenderem-se trabalhadores e a intervirem nas lutas pelos direitos do trabalho" (ARROYO, 2017, p. 143).

A relação dos estudos com o mercado de trabalho é uma constante preocupação dos estudantes, afinal, um dos grandes fatores que os levou a voltar aos bancos escolares é a dificuldade de acesso ou de progressão nos empregos por conta da 
escolarização: "me encontro desempregado e estava encontrando muita dificuldade em encontrar emprego por conta dos estudos" (Cristiano); é "difícil achar um serviço sem estudar" (Gustavo). Nesse sentido, alguns deles relataram que a EJA trouxe bons resultados para sua vida profissional:

Sobre essa etapa na EJA foi um passo muito importante [...] pois tive a oportunidade de recuperar o tempo perdido e ainda através dos estudos consegui uma vaga de emprego como jovem aprendiz, isso foi muito legal e importante profissionalmente. [...] a EJA me projetou não só para os estudos mas também para o mercado de trabalho (Ricardo).

Ricardo conta que, a partir da EJA, conseguiu o emprego como jovem aprendiz e que se encontrava feliz com os acontecimentos recentes de sua vida, pois já passara por muitas dificuldades - durante os estudos da EJA, inclusive, morava em uma casa de abrigo.

O que muitos alunos contam é a história de como retomaram sua confiança e passaram a acreditar que, para eles, é possível seguir os estudos e ter empregos melhores. A escola, que tanto os havia excluído e os considerado incapazes, agora é o espaço que os faz retomar as esperanças. Todos os 12 escritos analisados relatam a pretensão de continuar os estudos e seguir os projetos pessoais, inclusive, a maioria deles menciona o plano de ingressar em uma faculdade. Conforme já explicitado, todos os textos ora analisados são de alunos que estavam certificandose no segundo segmento da EJA e, portanto, tiveram bons resultados nas aulas e pesquisas. Nesse sentido é importante salientar que, infelizmente, um grande problema na EJA é a evasão, que ocorre por diversos motivos ${ }^{6}$. Entre os fatores da evasão deve-se considerar que pode também ser resultado da insatisfação discente com as aulas e com a metodologia. Assim, a forma de funcionamento da EJA não pode ser homogênea, precisa ser o mais variada possível para atender às diferentes demandas dos sujeitos que a compõem.

Desenvolveu-se, aqui, uma reflexão sobre a prática, pois acredita-se ser sempre necessário analisar e repensar os caminhos. Como afirma Freire (1996), “é pensando criticamente a prática de hoje ou de ontem que se pode melhorar a

\footnotetext{
${ }^{6}$ O problema da evasão é recorrente nos estudos sobre EJA, é complexo e envolve diversos fatores. Catelli, Di Pierro e Girotto (2019) classificaram em motivos intraescolares - "organização dos tempos e espaços de ensino-aprendizagem, especificidade do projeto pedagógico, formação docente, etc." - e extraescolares - "de ordem socioeconômica, cultural e psicossocial, que incidem sobre as trajetórias escolares e variam de acordo com marcadores de classe, gênero, raça e geração, sendo afetados também por influências das esferas de socialização (família, trabalho, escola) nos projetos de escolarização dos indivíduos" (CATELLI, DI PIERO; GIROTTO, 2019, p. 472).
} 
próxima prática. $\mathrm{O}$ próprio discurso teórico, necessário à reflexão crítica, tem de ser de tal modo concreto que quase se confunda com a prática" (FREIRE, 1996, p. 39). Como qualquer processo educativo, a metodologia da EJA da RMEF deve ser sempre (re) estudada e repensada à procura de formas de melhor desenvolvê-la e expandi-la. 


\title{
Research as an educational principle: $a$ work methodology for Youth and Adult Education
}

\begin{abstract}
The Youth and Adult Education reaches only a small portion of its demand, and one of the main issues that leads the public to not attend school classes is the inadequacy of methodologies and knowledge to their realities and objectives. In the Municipal Education of the city Florianópolis (SC), a different form of school work has been developed, which seeks to meet this need, called research as an educational principle. The goal of this article is to analyze this methodology, which has been adopted since 2001, going through its development, its theoretical references and some reflections on the school's daily practice. Aside from the theoretical research, this article uses reports of classroom experience and analysis of texts produced by some students in 2018, seeking to demonstrate some of the potential and limits of this practice. Therefore, it is believed that, from the further development of this methodology, it is possible to better analyze some demands and issues pertinent to Youth and Adult Education in Brazil.
\end{abstract}

Keywords: Youth and Adult Education. Research as Educational Principle. Pedagogical practices.

\section{La investigación como principio educativo: una metodología de trabajo para la Educación de Jóvenes y Adultos}

\section{Resumen}

La modalidad de Educación de Jóvenes y Adultos alcanza solo una pequeña porción de su demanda, siendo que uno de los factores que lleva al público a no asistir a las clases escolares es la inadecuación de metodologías y conocimientos a sus realidades y objetivos. En la Red Municipal de Educación de la ciudad de Florianópolis (SC), se desarrolla una forma distinta de trabajo escolar, que busca atender esta necesidad, se llama investigación como principio educativo. El objetivo de este artículo es analizar esta metodología adoptada por la red desde 2001, pasando por su desarrollo, sus referentes teóricos y algunas reflexiones sobre la práctica escolar cotidiana. Además de la investigación teórica, el artículo utiliza informes de la experiencia del aula y el análisis de textos producidos por algunos estudiantes en 2018, buscando demostrar algunas potencialidades y límites de la práctica. Así, se cree que, a partir de la profundización de esta metodología, es posible analizar mejor algunas demandas y cuestiones pertinentes a EJA en el país.

Palabras clave: Educación de Jóvenes y Adultos. La Investigación como Principio Educativo. Prácticas pedagógicas. 


\section{Referências}

ARROYO, M. Passageiros da noite: do trabalho para a EJA: itinerários pelo direito a uma vida justa. Petrópolis: Vozes, 2017.

BERGER, D. G. Trajetórias territoriais dos jovens da EJA. Dissertação (Mestrado em Educação) - Centro de Educação, Universidade Federal de Santa Catarina, Florianópolis, 2009.

CATELLI JUNIOR, R.; DI PIERRO, M. C.; GIROTTO, E. D. A política paulistana de EJA: territórios e desigualdades. Estudos em Avaliação Educacional, São Paulo, v. 30, n. 74, p. 454-484, maio/ago. 2019. https://doi.org/10.18222/eae.v30i74.5734

DEMO, P. Educar pela pesquisa. Campinas: Autores Associados, 1996.

FEITOSA, S. C. S. Das grades às matrizes curriculares participativas na EJA: os sujeitos na formulação da mandala curricular. Tese (Doutorado em Educação) - Faculdade de Educação, Universidade de São Paulo, São Paulo, 2012.

FLORIANÓPOLIS. Secretaria Municipal de Educação. Scretaria de Educação Continuada. Estrutura, funcionamento, fundamentação e prática na educação de jovens e adultos - EJA 2008. Florianópolis, 2008.

FREIRE, P. Pedagogia da autonomia: saberes necessários à prática educativa. São Paulo: Paz e Terra, 1996.

FREIRE, P.; FAUNDEZ, A. Por uma pedagogia da pergunta. Rio de Janeiro: Paz e Terra, 1985.

HADDAD, S.; DI PIERRO, M. C. Escolarização de jovens e adultos. Revista Brasileira de Educação, Rio de Janeiro: n. 14, p. 108-130, maio/ago., 2000.

MACHADO, M.M. A EJA no século XXI: da alfabetização ao ensino profissional. Inter-Ação, Goiânia, v. 36, n. 2, p. 393-412, jul./dez. 2011. https://doi.org/10.5216/ia.v36i2.16713

NUNES, J. M. C. P. Sujeitos da educação de jovens e adultos: produção da permanência no ensino médio regular noturno. Dissertação (Mestrado em Educação) - Universidade Federal de Santa Catarina, Florianópolis, 2010.

PASSOS, J. C. Juventude negra na EJA: os desafios de uma política pública. Florianópolis, SC, 2010. Tese (Doutorado em Educação) - Centro de Educação, Universidade Federal de Santa Catarina, Florianópolis, 2010. 
ZANELA, C. C.; BARCELOS, A. R. F. (orgs.). Proposta curricular da Rede Municipal de Ensino de Florianópolis - 2016. Florianópolis:. Secretaria de Educação, 2016.

\section{Informações sobre as autoras}

Cecília de Sousa Reibnitz: Mestra em História pela Universidade Federal de Santa Catarina. Professora substituta no Departamento de Educação de Jovens e Adultos da Rede Municipal de Educação de Florianópolis. Contato: cecilia.reibnitz@gmail.com

(iD https://orcid.org/0000-0002-5622-6530

Ana Carolina Staub de Melo: Doutora em Educação Científica e Tecnológica pela Universidade Federal de Santa Catarina. Professora do Instituto Federal de Santa Catarina. Contato: ana.melo@ifsc.edu.br

(iD) https://orcid.org/0000-0002-4268-4047 